SUSIGAN, Cristina. A Trans-Memória das Imagens, sentir o tempo e inquietar-se: o caso Sonderkommando. Domínios da Imagem, Londrina, v. 12, n. 22, p. 115-126, jan./jun. 2018.

ISSN 2237-9126

Recebido em 29/9/2017 e aprovado em 30/1 1/2018

\title{
A TRANS-MEMÓRIA DAS IMAGENS, SENTIR O TEMPO E INQUIETAR-SE: O CASO SONDERKOMMANDO
}

\section{THE TRANS-MEMORY OF IMAGES, FEEL TIME AND LOOK AFTER: THE SONDERKOMMANDO CASE}

Resumo: Se a memória se constituiu, desde o seu início, como um terreno privilegiado da história, ela não é menos importante para outras áreas do pensamento, como as artes. Se a história a utilizou e a integrou como um dos seus conceitos fundamentais, transformando-a num conceito operatório do pensamento, as artes permitem descrever a "vida póstuma" das formas da cultura e das manifestações artísticas. Relembro, Walter Benjamin e o seu conceito de "Rememoração", como o próprio conceito de Aby Warburg, nomeadamente o de "Imagem Sobrevivente", e aqui aparece uma outra componente, que se desdobra a partir daquela: a relação da imagem com a própria história e também a da memória que sobrevive nas imagens. Este artigo tem o intuito de analisar as quatro fotografias que foram realizadas pelos prisioneiros do campo de Auschwitz-Birkenau em risco de vida, os Sonderkommandos, mostrando que as imagens são a hipótese de reconstrução do testemunho.

Palavras-chaves: Trans-Memória das Imagens. Imagem Sobrevivente. Sonderkommando.

Abstract: If the memory was, since its inception, as a privileged terrain of history, it is no less important for other areas of thought, such as the arts. If history has used it and integrated it as one of its fundamental concepts, transforming it into an operative concept of thought, the arts allow us to describe the "posthumous life" of the forms of culture and a rtistic manifestations. Recall, Walter Benjamin and his concept of "Remembrance", like the very concept of Aby Warburg, namely the "Surviving Image", and here appears another component, which unfolds from that: the relation of the image to the story itself and also to the memory that survives in the images. This article intends to analyze the four photographs that were taken by prisoners of AuschwitzBirkenau camp at risk of life, the Sonderkommandos, showing that the images are the hypothesis of reconstruction of the testimony.

Keywords: Trans-Memory of Images. Survivor image. Sonderkommando.

- Cristina Susigan é doutora pelo Programa de Pós-Graduação em Educação, Arte e História da Cultura na Universidade Presbiteriana Mackenzie. Atuou como docente em Portugal, lecionando as disciplinas de Legislação e Autoria, Argumento e Linguagem Audiovisual, História do Cinema e Análise de Filmes. Atualmente leciona disciplinas ligadas a História da Arte. 
SUSIGAN, Cristina. A Trans-Memória das Imagens, sentir o tempo e inquietar-se: o caso Sonderkommando. Domínios da Imagem, Londrina, v. 12, n. 22, p. 115-126, jan./jun. 2018.

ISSN 2237-9126

Memória. Palavra que por si só carrega um conceito volátil. Do latim memoria, nos remete a rememorar; recordar; relembrar o passado. No sentido desta comunicação, tendo como ponto de análise quatro fotografias, iremos relembrar a imagem de Memória estabelecida por Cesare Ripa (Paris, 1643 [Pagina: I,107 (XCVI)]) em sua Iconologia, que se identifica com a figura de Mnemosine (a Musa da Memória) e de sua filha Polimnia, que simboliza a "memória persistente" (grifo da autora). Segundo Frances Amelia Yates, define memória de uma forma poética: "A memória está na sala dos tesouros de todas as coisas" (YATES, 2007, p. 25) e voltando ao campo das imagens, imagens que estão carregadas de memórias, por mais violentas e inaceitáveis que sejam, fazendo a análise das quatro fotografias do Sonderkommando que foram realizadas pelos prisioneiros de Birkenau em risco de vida, Martine Joly nos diz que:

(...) compreender também é um prazer, (...) a análise da imagem preenche funções diferentes e tão variadas como proporcionar prazer ao observador, aumentar seus conhecimentos, instruir, permitir a leitura ou conceber mais eficazmente mensagens visuais (JOLY, 2002, p.111).

Afinal estas imagens são testemunhos visuais aos quais deve-se prestar toda a atenção. São fontes visuais que podem ser utilizadas como um documento histórico, segundo Louis Marin, devido "(...) o ser da imagem, numa palavra, é a sua força" (MARIN,1998, p. 65). A memória das imagens produz traços de identificação e de identidade que ajudam a compreender sintomas de nostalgia, e portanto, para este estudo, recorreremos ao conceito de trans-memória, cunhado por Vitor Serrão, aplicado ao estudo das imagens artísticas, no qual: 
SUSIGAN, Cristina. A Trans-Memória das Imagens, sentir o tempo e inquietar-se: o caso Sonderkommando. Domínios da Imagem, Londrina, v. 12, n. 22, p. 115-126, jan./jun. 2018.

ISSN 2237-9126

(...) tendo em vista o entendimento de que a obra de arte, mais que um testemunho trans-contextual apto a formas novos públicos cada vez que é alvo de um novo acto de fruição, é também um laboratório de memórias acumuladas (grifo do autor), que sobrevivem e perduram, seja nas franjas do subconsciente, seja na prática da criação e da re-criação dos artistas. (SERRÃO, 2007,p. 11).

Serrão em seu conceito nos remete diretamente ao conceito de imagem sobrevivente (Nachleben) de Aby Warburg, com a sua circularidade. Segundo esta acepção warburguiana, que é encarada nos termos de uma memória de imagens que regressam constantemente como sintomas, apelando a uma psicologia histórica da expressão humana, a cultura seria um processo de sobrevivência - de Nachleben - isto é, de transmissão, recepção e polarização.

\section{A morte entranha-se na pele: os Sonderkommandos}

Os testemunhos dos Sonderkommandos são uma peça essencial na reconstituição das fábricas de extermínio montadas em alguns campos. No entanto, necessário será definir, se é possível usar esta denominação para atividade tão atroz e cruel, que é o grupo de pessoas que atuavam em campos de concentração nazistas a comando destes. Eram pessoas recrutadas entre os prisioneiros recentemente chegados e tinham como função a execução das tarefas como a preparação para o gaseamento, o transporte dos corpos para a incineração e, por fim, a dispersão das cinzas e de todos os restos, limpeza das câmaras de gás e outros serviços que os alemães se recusavam a executar. Devido a esta tarefa, eram considerados um grupo especial, obtendo alguns privilégios, primeiro viviam separadamente dos outros prisioneiros, tinham comida em abundância e de qualidade, vinho, cama, roupa, alojamento decente e apropriados ao rigor do inverno. O funcionamento do dispositivo industrial de extermínio montado em seis campos nazis (o de Auschwitz II- Birkenau é o mais conhecido) era garantido pelos Sonderkommandos. No Verão de 1944, quando chegaram a 
SUSIGAN, Cristina. A Trans-Memória das Imagens, sentir o tempo e inquietar-se: o caso Sonderkommando. Domínios da Imagem, Londrina, v. 12, n. 22, p. 115-126, jan./jun. 2018.

ISSN 2237-9126

Auschwitz mais de cinquenta trens de judeus húngaros, os Sonderkommandos contavam com um efetivo de 900 "operários" (grifo da autora) que asseguravam o funcionamento ininterrupto do aparelho de destruição.

Aos Sonderkommandos estava também atribuída a tarefa de queimar os objetos sem valor que os judeus traziam consigo, tais como livros, objetos pessoais, livros de orações, cartões de identidade. A "fábrica" (grifo da autora) não era apenas de extermínio, era também de extinção de todos os restos, de apagamento de todos os vestígios: a vontade de negação estava inscrita nos planos dos assassinos, é consubstancial ao genocídio. Em Os que Sucumbem e os que Se Salvam, diz Primo Levi: "O crime mais demoníaco do nacional-socialismo foi ter concebido essas equipes especiais" (LEVI, 2008, p. 136). Estes judeus que assistiram à destruição do seu próprio povo e, mais do que isso, ajudaram na sua execução, viveram no "coração do inferno" (grifo da autora). A questão da colaboração forçada dos judeus no seu próprio extermínio é das mais complexas da história do genocídio e tem sido motivo de grandes discussões. Umas das razões que explicam a escolha de judeus maioritariamente para a constituição dos Sonderkommandos é esta: era preferível que quem desempenhava tais tarefas falasse a mesma língua das vítimas para servir de mediador.

Apesar da colaboração com os nazistas, estes judeus não duravam muito nesta função, vindo a integrar a lista de pessoas a serem exterminadas após algum tempo de serviço, sendo substituídas por novos integrantes que mais adiante eram mortos. Shlomo Venezia, 86 anos é um dos poucos sobreviventes do campo de extermínio Auschwitz-Birkenau que teve uma das mais terríveis funções: ser um Sonderkommando. Oriundo da comunidade judaica italiana de Salonica, Venezia foi deportado para Auschwitz-Birkenau aos 21 anos e incorporado no Sonderkommando em Abril de 1944. Não foi o caso do impressionante caso de Venezia, que assistiu às piores e inimagináveis atrocidades jamais cometidas pelo homem. Mais de 60 anos depois dos acontecimentos, e apesar dos pesos de consciência derivados da sua função 
SUSIGAN, Cristina. A Trans-Memória das Imagens, sentir o tempo e inquietar-se: o caso Sonderkommando. Domínios da Imagem, Londrina, v. 12, n. 22, p. 115-126, jan./jun. 2018.

ISSN 2237-9126

no campo de extermínio, Shlomo Venezia resolveu contar em livro os pormenores da sua história de sofrimento e horror.

Outro sobrevivente, Filip Müller, que esteve três anos no "comando especial" (grifo da autora) e sobreviveu a cinco vagas de "transferências" (grifo da autora), é absolutamente singular, tão raro que serve de subtítulo às suas memórias: Eyewitness Auschwitz: Three years in the gas chambers (1979). E se as condições de vida dos Sonderkommandos eram, sem dúvida, bastante melhores do que a dos restantes detidos, devemos atentar mais de perto no exemplo de Shlomo Venezia: após a libertação, esteve internado em diferentes hospitais durante sete anos; e só quarenta e sete anos depois, na década dos anos de 1990, teve coragem de voltar a falar da sua experiência em Auschwitz-Birkenau:

Os outros sobreviventes sofreram seguramente muito mais fome e frio do que eu, mas não estavam constantemente em contato com os mortos. Aquela visão diária de todas aquelas vítimas gaseadas (...) nunca se sai verdadeiramente do Crematório. (VENEZIA, 2010, p. 187)

Os sobreviventes dos Sonderkommandos tiveram de carregar consigo uma dupla culpabilidade: a de terem sobrevivido, sentimento muito comum às vítimas da Endlösung; e, a acrescer a isso, o fardo de terem pertencido aos esquadrões que conduziam os seus semelhantes ao interior das câmaras de gás ou às fossas onde seriam baleados a sangue-frio. Eram eles, para mais, os que corriam o maior risco: na lógica do sistema dos campos, nenhum membro do Sonderkommando poderia ou iria sobreviver. O seu tempo vital estava marcado à partida - três, quatro meses -, enquanto os demais prisioneiros não tinham um horizonte de morte predefinido. Desde que foram instituídos até à evacuação dos campos, existiram em Auschwitz cerca de catorze gerações de Sonderkommandos. Aos detidos era dito regularmente que dali ninguém sairia vivo para testemunhar fosse o que fosse. Eis a razão pela qual praticamente todos os membros dos Sonderkommandos eram judeus: se o não fossem, não existiria a garantia a priori de que, no final, todos iriam morrer. 
SUSIGAN, Cristina. A Trans-Memória das Imagens, sentir o tempo e inquietar-se: o caso Sonderkommando. Domínios da Imagem, Londrina, v. 12, n. 22, p. 115-126, jan./jun. 2018.

ISSN 2237-9126

Segundo Walter Benjamin: "Nunca houve um documento da cultura que não fosse também um documento da barbárie. E, assim como a cultura não é isenta de barbárie, não o é, tampouco, o processo de transmissão da cultura" (BENJAMIN, 1996, P. 222), pois os processos históricos e sociais ganham forma e visibilidade e as quatro fotografias que chegaram aos nossos dias e revelam os procedimentos nos campos de concentração vem corroborar esta afirmação.

\section{Imagens apesar de tudo}

Em agosto de 1944, membros do Sonderkommando deixaram-nos quatro fotografias tiradas em Birkenau registrando o processo de extermínio em curso nas câmaras de gás. À luz da questão: ver (voir) uma imagem pode ajudar-nos a conhecer (savoir) melhor?, escrutinam-se as horrendas condições de vida e de morte nos campos de concentração e nas câmaras de gás, as peripécias que rodearam a captura e transmissão destas fotografias, e constrói-se uma fenomenologia das mesmas. Apesar das lacunas documentais e do interdito constituído pelo famigerado carácter «inimaginável» da Shoah, a experiência dos campos suscitou a imaginação, o que importa compreender para que se compreenda o valor das imagens tão necessárias quanto lacunares - na história e na constituição do conhecimento histórico.

Desconhece-se como a câmara fotográfica entrou no campo. Há quem diga que foi obtida no "Kanada" (grifo da autora), o gigantesco depósito dos pertences roubados às vítimas. Outros falam num trabalhador civil polaco, que trabalhava nas imediações e conseguiu passar a máquina a um preso, uma vez que os chefes da Resistência na Polónia há muito pediam fotografias dos campos para transmitir aos Aliados. Sabe-se que foi um grego, 
SUSIGAN, Cristina. A Trans-Memória das Imagens, sentir o tempo e inquietar-se: o caso Sonderkommando. Domínios da Imagem, Londrina, v. 12, n. 22, p. 115-126, jan./jun. 2018.

ISSN 2237-9126

"Alex" - que se supõe ser o oficial de marinha Alberto Israel Errera (1913-1944)1 -, que captou as imagens, com mãos trêmulas, dando seu testemunho da barbárie que acontecia dentro dos campos, fato até então desconhecido do resto do mundo, e acabou por ser morto após ter conseguido evadir-se de Birkenau. A 04 de setembro de 1944, os negativos das fotografias de "Alex" chegaram às mãos da Resistência polonesa na Cracóvia, traficados dentro de um tubo de pasta de dente.

As fotos em preto e branco, publicadas em papel poroso e amarelado, são a expressão justa daquilo que sobreviveu, das imagens clandestinas capturadas pelos membros do Sonderkommando, e fizeram parte da exposição Memoire des camps - Photographies des camps de concentration et d'extermination nazis 1933-1999, realizada em 2001 em Paris5, e que compõe a primeira parte do livro de Georges Didi-Huberman, Imagens Apesar de Tudo². Se o projeto nazista era não deixar rastros do extermínio em massa para torná-lo "inimaginável", argumenta o filósofo, então as fotos dos prisioneiros "dirigem-se ao inimaginável, refutando-o" (DIDI-HUBERMAN, 2012, p. 29). Por isso, Auschwitz não é inimaginável. Auschwitz é senão imaginável. $E$ isso significa não uma negação da negação, mas um apelo, um chamado à tarefa - tão insuportável quanto necessária - de nos colocarmos a imaginar. Recorrendo a Hannah Arendt, Didi-Huberman defende que se Auschwitz ultrapassa toda noção de justiça e humanidade, é preciso repensar o direito e as ciências humanas, pois ali onde "fracassa o pensamento" e surge a tentação do impensável "é onde devemos preservar o pensamento". "Para saber é preciso imaginar". Ou ainda, saber que devemos aprender a "dominar o dispositivo das imagens para saber o que fazer com nosso saber e com nossa memória" (DIDI-HUBERMAN, 2012, p. 226)

\footnotetext{
1 Alex, é identificado, segundo todas as probabilidades, por Alberto Errera, judeu grego nascido em 15 de janeiro de 1913 em Larissa e membro ativo da resistência grega. Capturado em 24 ou 25 de março de 1944, foi deportado à Auschwitz-Birkenau em 9 de abril e selecionado como membro do Sonderkommando do Crematório $V$ para exercer a função de "chauffeur" (grifo da autora), quer dizer, trabalhador nos fornos crematórios.

2 Foi publicado originalmente no catálogo que acompanhava a exposição.
} 
SUSIGAN, Cristina. A Trans-Memória das Imagens, sentir o tempo e inquietar-se: o caso Sonderkommando. Domínios da Imagem, Londrina, v. 12, n. 22, p. 115-126, jan./jun. 2018.

ISSN 2237-9126

Das quatro imagens registradas, sabemos que três delas foram reenquadradas pelo próprio Museu de Estado de Auschwitz-Birkenau, para que pudessem melhor servir como "informação", como "documento", numa supressão problemática - como tanto ressalta Didi-Huberman - do gesto daquele que, sabendo que desapareceria como testemunha, precisou nos transmitir seu trágico testamento. O reenquadramento gera sérias controvérsias, pois ao colocar a moldura negra, suprime as reais condições de sua produção - um olhar temeroso mas que ao mesmo tempo arrisca-se a captar um momento histórico, que perdurou até os nossos dias, através da ousadia de um judeu que trabalhava nas "forças especiais" (grifo da autora) -, pois produz a sensação que a imagem foi feita do exterior e portanto por parte de um nazista. Para Georges Didi-Huberman, o gesto do fotógrafo clandestino foi, no final das contas, tão simples quanto heroico, pois, ao se posicionar dentro de uma câmera de gás, justamente onde os nazistas o abrigavam, dia após dia, a descarregar os cadáveres das vítimas assassinadas, "ele transformou, por alguns raros segundos roubados, o trabalho servil, seu trabalho de escravo de inferno, num verdadeiro trabalho de resistência" (DIDI-HUBERMAN, 2012, p. 124). Sendo assim, pergunta-se, seu ato de testemunho não deveria ser compreendido como um minúsculo deslocamento do trabalho de morte em trabalho de olhar?

Em duas das fotografias abaixo (Figura 01 e 02), mostram corpos esperando para ser queimados. Os corpos eram queimados em fogueiras ao ar livre quando os crematórios estavam cheios e posteriormente cabia as "equipes especiais" (grifo da autora) a tarefa de limpar o local. Na Figura 03, vemos mulheres, desnudas e desesperadas, sendo levadas para a câmara de gás, correm para o seu próprio fim. Na Figura 04, temos um recorte desfocado, umas árvores e talvez a fumaça dos corpos sendo queimados. 
SUSIGAN, Cristina. A Trans-Memória das Imagens, sentir o tempo e inquietar-se: o caso Sonderkommando. Domínios da Imagem, Londrina, v. 12, n. 22, p. 115-126, jan./jun. 2018.

ISSN 2237-9126

Figura 01 - Frame da câmera de gás feito de uma janela pelos Sonderkommando, 1944.

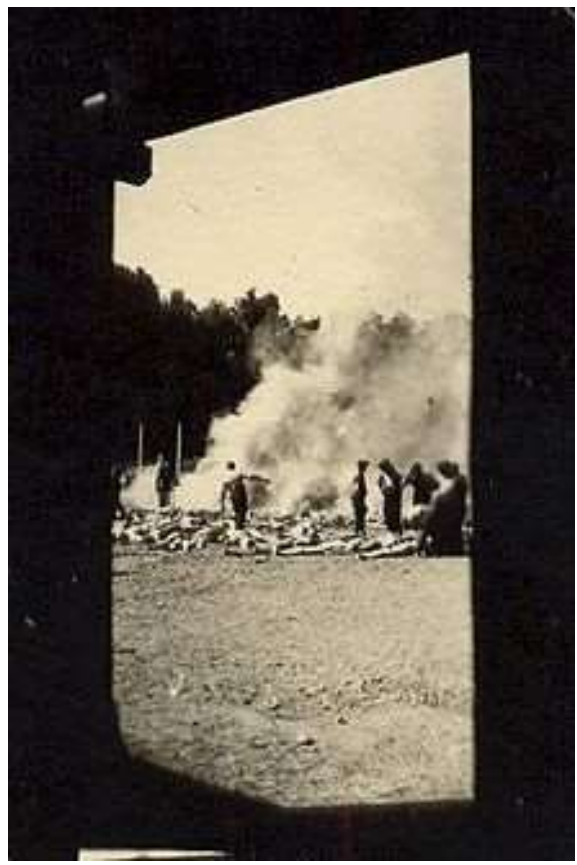

Fonte: Arquivo do Museu Auschwitz/ Birkenau. Autor: Alex, membro do Sonderkommando.

Figura 02 - Frame da câmera de gás feito de uma janela pelos Sonderkommando, 1944.

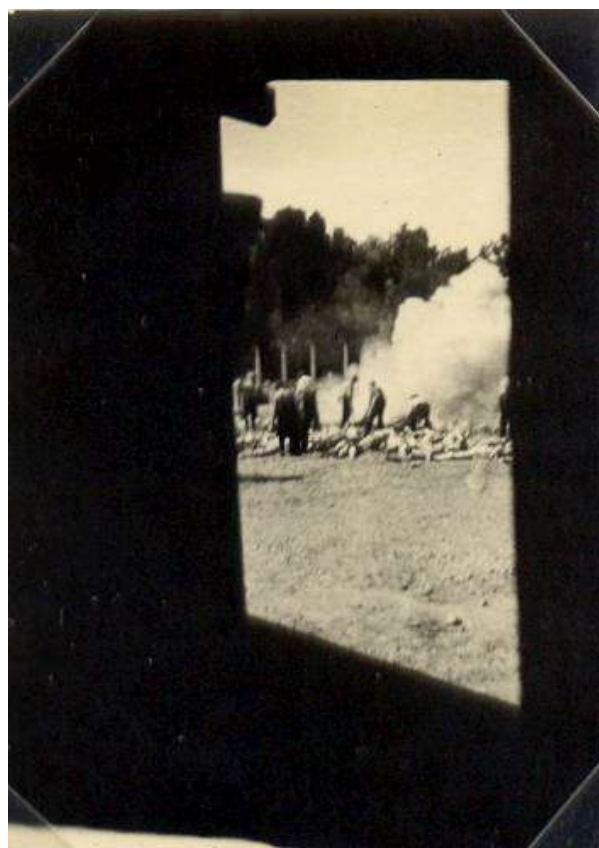

Fonte: Arquivo do Museu Auschwitz/ Birkenau. Autor: Alex, membro do Sonderkommando 
SUSIGAN, Cristina. A Trans-Memória das Imagens, sentir o tempo e inquietar-se: o caso Sonderkommando. Domínios da Imagem, Londrina, v. 12, n. 22, p. 115-126, jan./jun. 2018.

Figura 03 - Frame da câmera de gás feito de uma janela pelos Sonderkommando,1944.

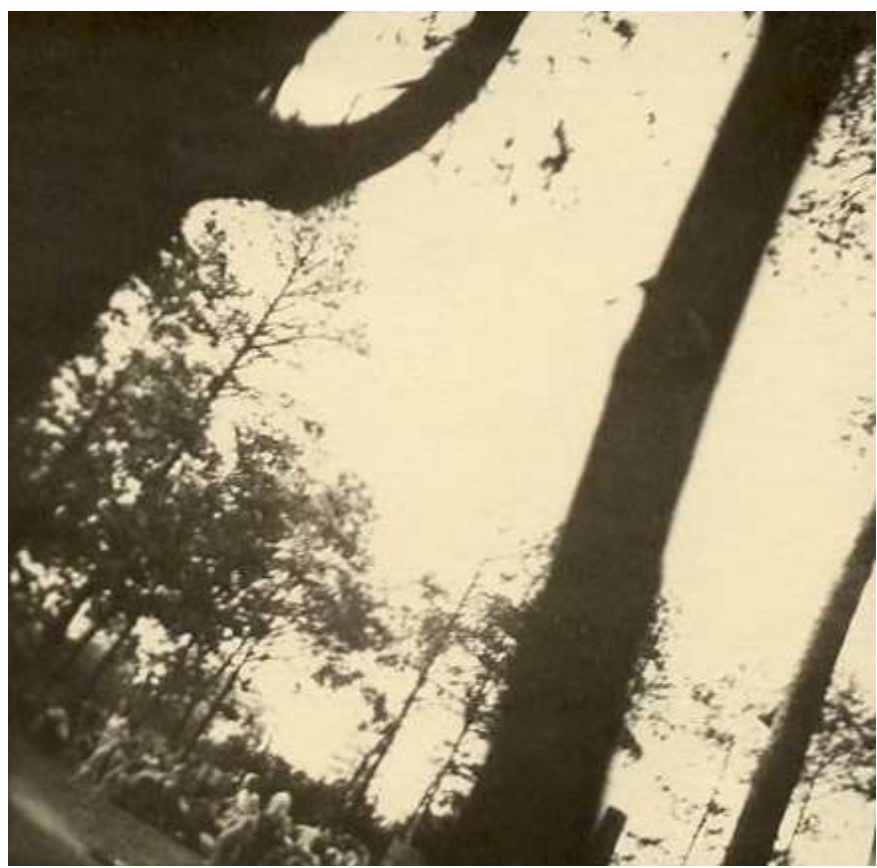

Fonte: Arquivo do Museu Auschwitz/ Birkenau. Autor: Alex, membro do Sonderkommando

Figura 04 - Frame da câmera de gás feito de uma janela pelos Sonderkommando, 1944.

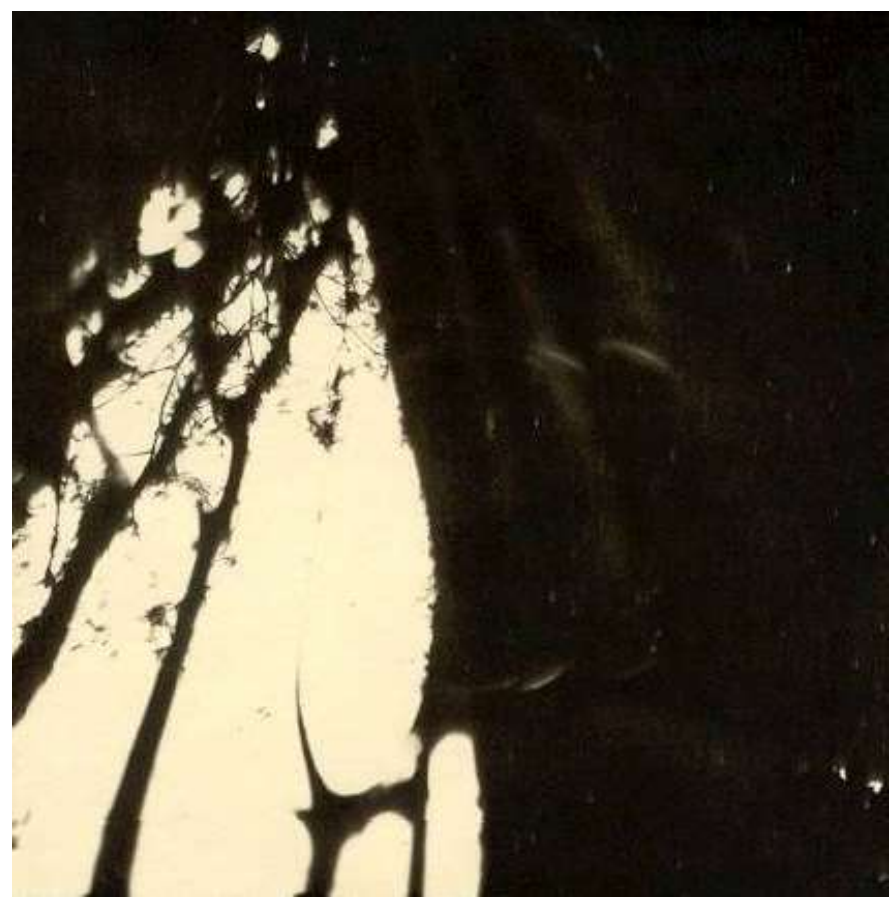

Fonte: Arquivo do Museu Auschwitz/ Birkenau. Autor: Alex, membro do Sonderkommando. 
SUSIGAN, Cristina. A Trans-Memória das Imagens, sentir o tempo e inquietar-se: o caso Sonderkommando. Domínios da Imagem, Londrina, v. 12, n. 22, p. 115-126, jan./jun. 2018.

ISSN 2237-9126

\section{Considerações Finais}

Didi-Huberman defende que as imagens podem revelar o real, pelo menos de alguma forma (DIDI-HUBERMAN, 2012). Só assim, diz Didi-Huberman, o visitante atual de Auschwitz entende que não caminha apenas em um museu, e sim "no maior cemitério do mundo". Analisar imagens antigas é como andar por uma ruína. Quase tudo está destruído, mas resta algo. O importante é como nosso olhar põe esse algo em movimento. Quem não sabe olhar atravessa a ruína sem entender e concluí:

(...) Não há imagens que, em si, nos deixariam mudos, impotentes. Uma imagem a respeito da qual não poderíamos dizer nada é geralmente uma imagem para a qual não lhe dedicamos o tempo - mas esse tempo é longo, ele demanda coragem, repito - de olhar atentamente. De re-inquietar-se a cada instante. (DIDI-HUBERMAN, 2006, s/n)

Costumamos pensar que as imagens devem mostrar algo reconhecível, mas elas são mais do que isso. São gestos, atos de fala. As sombras e a falta de foco dessas fotos mostram a urgência e o perigo com que foram feitas. Eliminar isso com o pretexto de que prejudicam a visibilidade é errado. Essas fotos são testemunhos, e é desonesto cortar a fala de uma testemunha. Temos que escutar também seus silêncios (DIDI-HUBERMAN, 2003, s/p).

\section{Referências}

BENJAMIN, Walter. Sobre o conceito de história. In: Obras escolhidas I: Magia e técnica, arte e política. São Paulo: Brasiliense, 1996.

DIDI-HUBERMAN, Georges. Imagens apesar de tudo. Trad. Vera Brito e J. P. Cachopo. Lisboa: KKYM, 2012.

- Georges Didi-Huberman fala sobre imagens e memórias do Holocausto. O Globo, 16 mar. 2003. Entrevista concedida a Guilherme Freitas. Disponível em: http://blogs.oglobo.globo. com/prosa/post/georgesdidihuberman-fala-sobreimagens-memorias-doholocausto-489909.html. Acesso em 25 mar. 2017. 
SUSIGAN, Cristina. A Trans-Memória das Imagens, sentir o tempo e inquietar-se: o caso Sonderkommando. Domínios da Imagem, Londrina, v. 12, n. 22, p. 115-126, jan./jun. 2018.

ISSN 2237-9126

Georges Didi-Huberman fala sobre as imagens do Holocausto. Revista Vacarme, n. 37, outono de 2006. Entrevista concedida a Mathieu Potte-Bonneville \& Pierre Zaoui. Trad. Vinícius Nicastro Honesko. Disponível em: http://www.vacarme.org/articlel210.html. Acesso em 1 mar. 2015.

JOLY, Martine. Introdução à Análise da Imagens. 11. edição. Campinas: Editora Papirus, 2002.

LEVI, Primo. Os que Sucumbem e os que se Salvam. Lisboa: Editorial Teorema, 2008.

MARIN, Louis. Des Pouvoirs De L'Image. Glosses. Paris: Éditions du Seul, 1998.

RIPA, Cesare. Iconologia. Disponível em: http://lartte.sns.it/ripa/lconologia_db/dettagli_lettera.php?id=m\#memoria. Acesso em 18 dez. 2018.

SERRÃO, Vitor. A Trans-Memória das Imagens. Estudos Iconológicos de Pintura Portuguesa (Séculos XVI-XVIII). Lisboa: Edições Cosmos, 2007.

VENEZIA, Shlomo. Sonderkommando. No Inferno das Câmaras em Gás. São Paulo: Editorial Objetiva, 2010.

YATES, Frances A. A Arte da Memória. Campinas: UNICAMP, 2007. 